\title{
The association of coffee intake with liver cancer incidence and chronic liver disease mortality in male smokers
}

\author{
G Y Lai ${ }^{*, 1,2}$, S J Weinstein ${ }^{2}$, D Albanes ${ }^{2}$, P R Taylor ${ }^{3}$, K A McGlynn $^{4}$, J Virtamo ${ }^{5}$, R Sinha ${ }^{2}$ and N D Freedman ${ }^{2}$ \\ ${ }^{1}$ Cancer Prevention Fellowship Program, Division of Cancer Prevention, National Cancer Institute, 9609 Medical Center Drive, \\ Room 2W136 MSC 9712, Bethesda, MD 20892, USA; ${ }^{2}$ Nutritional Epidemiology Branch, Division of Cancer Epidemiology and \\ Genetics, National Cancer Institute, 9609 Medical Center Drive, Room 1E326, MSC 9704, Bethesda, MD 20892, USA; ${ }^{3}$ Genetic \\ Epidemiology Branch, Division of Cancer Epidemiology and Genetics, National Cancer Institute, 9609 Medical Center Drive, \\ Room 6E444, Bethesda, MD 20892, USA; ${ }^{4}$ Hormonal and Reproductive Epidemiology Branch, Division of Cancer Epidemiology \\ and Genetics, National Cancer Institute, 9609 Medical Center Drive, Room 7E104, Bethesda, MD 20892, USA and ${ }^{5}$ Department of \\ Chronic Disease Prevention, National Institute for Health and Welfare, Helsinki, Finland
}

Background: Coffee intake is associated with reduced risk of liver cancer and chronic liver disease as reported in previous studies, including prospective ones conducted in Asian populations where hepatitis B viruses ( $\mathrm{HBVs}$ ) and hepatitis C viruses (HCVs) are the dominant risk factors. Yet, prospective studies in Western populations with lower HBV and HCV prevalence are sparse. Also, although preparation methods affect coffee constituents, it is unknown whether different methods affect disease associations.

Methods: We evaluated the association of coffee intake with incident liver cancer and chronic liver disease mortality in 27037 Finnish male smokers, aged 50-69, in the Alpha-Tocopherol, Beta-Carotene Cancer Prevention Study, who recorded their coffee consumption and were followed up to 24 years for incident liver cancer or chronic liver disease mortality. Multivariate relative risks (RRs) and 95\% confidence intervals (Cls) were estimated by Cox proportional hazard models.

Results: Coffee intake was inversely associated with incident liver cancer (RR per cup per day $=0.82,95 \%$ Cl: 0.73-0.93; $P$-trend across categories $=0.0007)$ and mortality from chronic liver disease $(R R=0.55,95 \% \mathrm{Cl}: 0.48-0.63 ; P$-trend $<0.0001)$. Inverse associations persisted in those without diabetes, HBV- and HCV-negative cases, and in analyses stratified by age, body mass index, alcohol and smoking dose. We observed similar associations for those drinking boiled or filtered coffee.

Conclusion: These findings suggest that drinking coffee may have benefits for the liver, irrespective of whether coffee was boiled or filtered.

Liver cancer is the sixth most commonly diagnosed cancer and the third leading cause of cancer death in the world (Ferlay et al, 2010). Traditionally, liver cancer rates have been high in regions with endemic hepatitis B virus (HBV) infection, such as countries in sub-Saharan Africa or Asia (McGlynn et al, 2001). In recent times, however, rates have increased in countries with low HBV prevalence, such as those in North America and Europe (McGlynn et al, 2001), likely due to infection with hepatitis C virus (HCV), obesity and diabetes (El-Serag and Rudolph, 2007). As liver cancer often arises from within livers damaged by chronic liver disease over the course of many years (Siegel and Zhu, 2009), it is vital to consider both chronic liver disease and liver cancer for cancer prevention.

A number of recent studies have suggested that coffee intake benefits liver health. Coffee consumption has been reported to be inversely associated with enzymes indicative of liver disease and 
damage (Arnesen et al, 1986; Kono et al, 1994; Poikolainen and Vartiainen, 1997; Tanaka et al, 1998; Nakanishi et al, 2000; Ruhl and Everhart, 2005), fibrosis and cirrhosis in cross-sectional studies (Modi et al, 2010; Muriel and Arauz, 2010), and liver disease progression (Freedman et al, 2009). Coffee may also be associated with lower cancer risk. Several prospective cohort studies in Asian populations with high HBV prevalence observed inverse associations between high or regular coffee consumption and liver cancer (Bravi et al, 2007; Larsson and Wolk, 2007). Studies in Western populations with a different spectrum of liver disease risk factors are limited, although a few case-control studies in Italy and Greece and one prospective cohort study in Finland support an inverse association for coffee and liver cancer (Bravi et al, 2007, 2009; Larsson and Wolk, 2007; $\mathrm{Hu}$ et al, 2008). The reported inverse association may be due to the anti-proliferative properties of a number of coffee compounds such as chlorogenic acid (Iwai et al, 2004) and diterpenes (e.g., cafestol and kahweol; Cavin et al, 1998, 2002; Majer et al, 2005). Yet, it has also been reported that different methods of coffee preparation can influence levels of these and other compounds (Ratnayake et al, 1993; Urgert et al, 1995; Gross et $a l, 1997)$ and preparation method has been shown to affect associations of coffee consumption with lipid levels and blood pressure in previous studies (Jee et al, 2001; Noordzij et al, 2005). However, little is known about whether the association of coffee intake with the risk of chronic liver disease or liver cancer is affected by preparation method.

We evaluated associations between coffee intake and subsequent risk of incident liver cancer or chronic liver disease mortality in the Alpha-Tocopherol, Beta-Carotene Cancer Prevention (ATBC) Study, a prospective cohort of Finnish male smokers that also had available data on coffee preparation methods.

\section{MATERIALS AND METHODS}

Participants, follow-up and outcome ascertainment. The rationale and design of the ATBC Study have been described previously (The ATBC Cancer Prevention Study Group, 1994). In short, the ATBC Study was a randomised, double-blinded, $2 \times 2$ factorial designed, placebo-controlled trial that evaluated whether vitamin $\mathrm{E}$ in the form of $\alpha$-tocopherol and $\beta$-carotene would reduce the risk of lung cancer. A total of 29133 Finnish male smokers with no prior malignancy, alcoholism or other major medical problems were enrolled at baseline between 1985 and 1988. Although the trial ended on 30 April 1993, the men were further followed-up through national registers for morbidity and mortality end points.

Men diagnosed with liver cancer $(n=194$; ICD-9 $=155$ and ICD-10 $=\mathrm{C} 22$ ) were identified through the Finnish Cancer Registry, providing close to $100 \%$ case ascertainment (Korhonen et al, 2002). The medical records of $80 \%$ of the liver cancer cases (i.e., those diagnosed during the trial and 6 years post-intervention) were reviewed by a study physician to confirm the diagnosis of liver cancer while incident data from the remaining 20\% was available only from the Finnish Cancer Registry. Follow-up time began at randomisation until the date of cancer diagnosis, death or until 31 December 2009, whichever came first. Men who died from chronic liver disease $(n=213$; ICD- $9=571$ and ICD-10 $=\mathrm{K} 70$, K73 or K74) were identified through the Finnish Register of Causes of Death. The underlying cause of approximately $90 \%$ of the chronic liver disease deaths was noted as alcohol-related liver diseases. Follow-up time began at randomisation until the date of death (from chronic liver disease for the cases or other causes for the controls), incident liver cancer or until 31 December 2009, whichever came first. After excluding those who reported liver cirrhosis and who lacked information on demographics or coffee intake, we had an analytic sample of 27037 men (93\% of the cohort; Figure 1). A total of eight men were diagnosed with incident liver cancer and also died from chronic liver disease. For our study, these men were considered to have incident liver cancer but were not included in the chronic liver disease mortality category. Information on the method of coffee preparation was available for 20737 men.

Written informed consent was provided by all participants before randomisation. The institutional review board of both the National Public Health Institute of Finland and the US National Cancer Institute approved the ATBC Study.

Data collection and laboratory analysis. At baseline, participants were asked to complete a questionnaire concerning their medical history, diet, tobacco smoking and alcohol consumption. Intake of coffee, alcohol, tea and other foods was calculated from a food

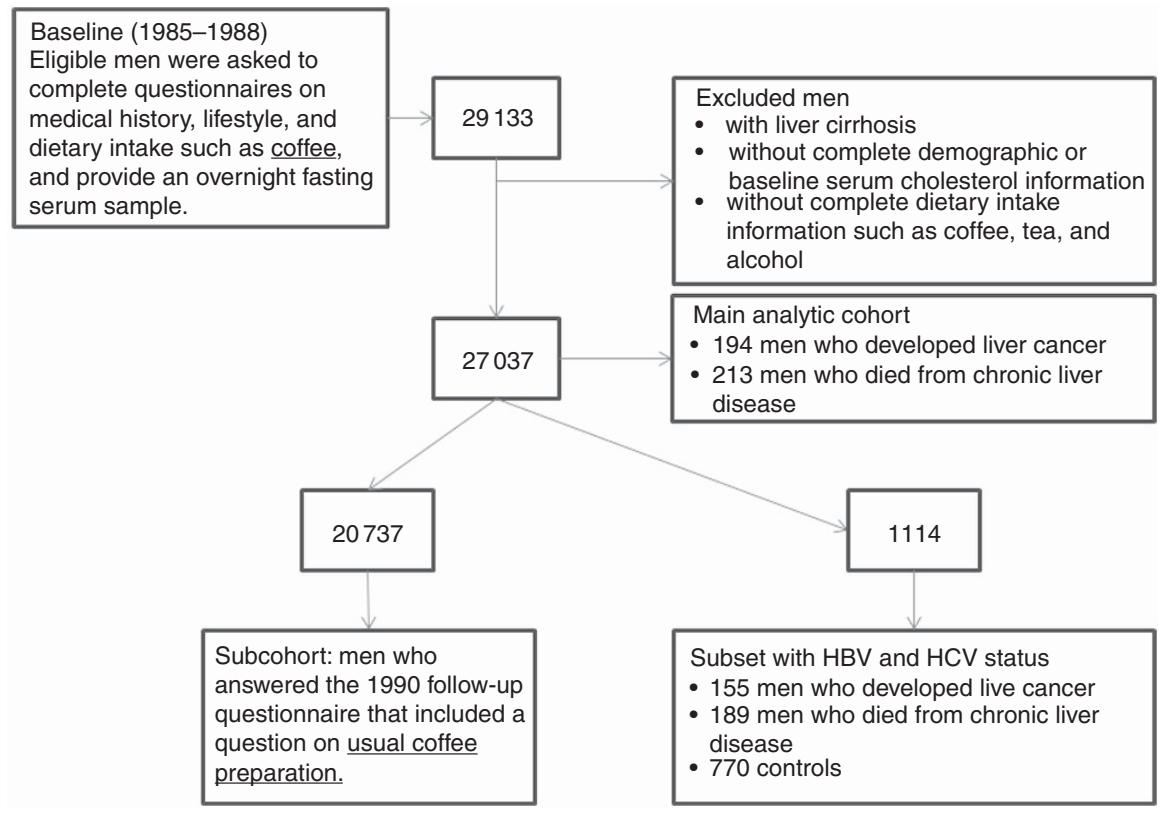

Figure 1. Diagram of analytic sample within ATBC Study. 
frequency questionnaire in conjunction with a validated comprehensive nutrient database. Within the questionnaire, participants were asked to indicate the average number of cups of coffee consumed per day or per week in the previous year. With the use of a colour picture booklet, participants were also asked to indicate their typical cup size. The three cup sizes most commonly used in Finland for coffee were 70, 110 and $170 \mathrm{~g}$. For coffee intake, the intraclass correlation coefficient comparing food records with food use questionnaires ranged from 0.72 to 0.79 (Pietinen et al, 1988). Each participant also provided an overnight fasting serum sample that was stored at $-70^{\circ} \mathrm{C}$. Total cholesterol was measured using an enzymatic assay (CHOD-PAP method, Boehringer Mannheim, Germany). Over the course of the trial, participants visited local centres every 4 months to complete follow-up questionnaires. In the fall of 1990 (2-5 years after randomisation), participants were asked about the usual method of preparing coffee at baseline with the following answer choices: 'usually filtered', 'usually boiled', 'usually instant' and 'I don't drink coffee'. Among these men, $71 \%$ and $21 \%$ reported filtered and boiled methods of preparation, respectively. Coffee prepared by filtered methods involves pouring water over roasted, ground coffee beans contained within a filter (nearly always paper). Coffee prepared by boiling methods involves pouring hot water onto ground coffee in a pot or cup, waiting until the grounds settle and then drinking the supernatant.

Serologic determinations were conducted in a subset of the cases (men who were diagnosed with liver cancer and men who died from chronic liver disease) and controls, frequency (2:1) matched by age ( \pm 5 years) and date of blood draw ( \pm 30 days). Testing for HBV surface antigen (HBsAg), antibody to hepatitis B core antigen (anti-HBc) and antibody to HCV (anti-HCV) was performed by the SAIC NCI-Frederick National Laboratory (Frederick, MD, USA). HBsAg was tested using enzyme immunoassay from Bio-Rad Laboratories (Redmond, WA, USA), and anti-HBC and anti-HCV were tested using enzyme-linked immunosorbent assays from Ortho-Clinical Diagnostics (Raritan, NJ, USA). Concordance of samples with known HBV and HCV status were perfect. Information on HBV and HCV was available in 155 men who developed liver cancer, 189 men who died from chronic liver disease, and 770 controls.

Statistical analysis. After excluding participants with missing demographic or serum data, our final analytic sample was 27037 men. Baseline demographic, behavioural and lifestyle factors as well as serum levels of cholesterol by intake of coffee are presented. Using the USDA conversion tables, we calculated that one cup of coffee (one cup being $8 \mathrm{oz}$ ) was approximately $237 \mathrm{~g}$. Relative risks (RR) and 95\% confidence intervals (CIs) for the association of coffee intake with incident liver cancers or mortality from chronic liver disease were estimated by Cox proportional hazard regression models with person-years as the underlying time metric. We tested the proportional hazards assumption by modelling the interaction of coffee consumption with follow-up time and observed no significant deviations. We used coffee drinkers who drank $<1$ cup per day $(>0-<1$ cup) as the referent group. Linear trend tests across increasing number of cups of coffee were estimated by assigning each participant the median intake of his category and entering that term as a continuous variable in the regression model. In the subset with information on HBV and HCV status, odds ratios and 95\% CIs were estimated by logistic regression models.

We examined risk estimates from crude and multivariable models that were adjusted for a number of known and possible confounders including: intervention arm, age (continuous), body mass index (BMI; continuous), education (elementary school or less, greater than elementary school), marital status (currently married, not currently married), history of diabetes (yes, no), years of smoking (continuous), number of cigarettes smoked per day (continuous), alcohol intake (continuous), tea intake (never drinker, up to $6 \mathrm{oz}$ of tea per day, $>6 \mathrm{oz}$ of tea) and total serum cholesterol level (continuous). These variables were evaluated because they are either known or are suspected risk factors for liver cancer and chronic liver disease (Chuang et al, 2009; Souza et al, 2012) or were associated with coffee intake. We further adjusted for hepatitis $\mathrm{B}$ and $\mathrm{C}$ status among the subset of men with this information. As $\mathrm{HBV}$ and $\mathrm{HCV}$ are associated with both liver cancer and chronic liver disease, we also evaluated the association among HBV- and HCV-negative participants. Lag analyses were conducted by evaluating associations after removing the first 2 and 5 years of follow-up, and among the first 10 years and last 10 years of follow-up. To consider possible effect modification, we evaluated associations by subgroups defined as above or below the median for age, BMI, years of smoking, number of cigarettes smoked per day, alcohol intake and serum cholesterol. Effect modification was formally tested by using likelihood ratio tests that compared regression models with and without the cross-product term for categorical coffee intake and the categories of each examined exposure.

Statistical tests were two-sided and considered statistically significant at $P$-value $<0.05$. All analyses were performed using SAS software, version 9.3 (SAS Institute, Cary, NC, USA).

\section{RESULTS}

After a median follow-up time of 18.2 years, 194 men developed liver cancer and 213 men died from chronic liver disease. Coffee intake ranged from 0 to 4 or more cups per day, with a median level of 2.3 cups per day (interquartile range $=1.8-3.2$ cups per day); approximately $2.5 \%$ of the participants were non-drinkers. At baseline, men were generally similar in age, BMI, the number of years smoked, the number of cigarettes smoked per day and proportion of those with a history of diabetes across categories of coffee consumption (Table 1). In contrast, men who consumed more coffee tended to be less educated, drink less alcohol, drink less tea and have higher serum cholesterol levels. A notable proportion of men, 64\%, reported drinking no tea. Among the subset of men with information on hepatitis B and C status, the prevalence of $\mathrm{HBsAg}$ was $0.8 \%$ and the prevalence of $\mathrm{HCV}$ seropositivity was $1.6 \%$.

Associations were similar in both crude and multivariate adjusted models. In multivariate models, the risks for incident liver cancer and mortality from chronic liver disease decreased with increasing coffee consumption (RR per cup per day $=0.82$, 95\% CI: $0.73-0.93$ and RR per cup per day $=0.55,95 \% \mathrm{CI}$ : $0.48-0.63$, respectively; Table 2 ). For liver cancer, associations were similar for those drinking $2-<3$ cups $(2-<3$ cups per day $v s$ $>0-<1$ cup per day $\mathrm{RR}=0.44,95 \%$ CI: $0.26-0.77)$ or more per day $(\geqslant 4$ cups per day $v s>0-<1$ cup per day $\mathrm{RR}=0.53,95 \%$ $\mathrm{CI}=0.30-0.95)$. In a sensitivity analysis, we restricted the analysis to only hepatocellular carcinoma cases ( $n=140$ cases) and observed similar estimates. In contrast, for chronic liver disease mortality, the RR became progressively lower with higher intake; men who drank $>4$ cups per day were at a significantly decreased risk $(\mathrm{RR}=0.07,95 \% \mathrm{CI}=0.03-0.15, \quad P$-value trend $<0.0001)$. The association remained similar in analysis restricted to men without a reported history of diabetes. In the subset of men with information on HBV and HCV, associations did not appreciably change when we adjusted for $\mathrm{HBV}$ and $\mathrm{HCV}$, or when the analysis were restricted to those lacking HBsAg (men diagnosed with liver cancer: 98.7\%; men who died from chronic liver disease: $99.6 \%$; controls: $99.2 \%$ ), or $\mathrm{HCV}(93.7 \%, 96.8 \%, 99.6 \%$, of cases and controls, respectively; Supplementary Table 1).

To account for the possibility that any underlying disease may influence coffee consumption, lag analyses were performed. Associations were similar after removing the first two (incident 
Table 1. Selected baseline characteristics of men by level of coffee consumption, ATBC Study

\begin{tabular}{|c|c|c|c|c|c|c|c|c|c|c|c|c|}
\hline \multirow{3}{*}{$\begin{array}{l}\text { No. of } \\
\text { participants }\end{array}$} & \multicolumn{2}{|c|}{ Never drinkers } & \multicolumn{2}{|c|}{$\begin{array}{c}0-<1 \text { cup } \\
\text { per day }\end{array}$} & \multicolumn{2}{|c|}{$\begin{array}{c}1-<2 \text { cups } \\
\text { per day }\end{array}$} & \multicolumn{2}{|c|}{$\begin{array}{c}2-<3 \text { cups } \\
\text { per day }\end{array}$} & \multicolumn{2}{|c|}{$\begin{array}{c}3-<4 \text { cups } \\
\text { per day }\end{array}$} & \multicolumn{2}{|c|}{$\begin{array}{l}\geqslant 4 \text { cups } \\
\text { per day }\end{array}$} \\
\hline & \multicolumn{2}{|c|}{667} & \multicolumn{2}{|c|}{3094} & \multicolumn{2}{|c|}{7204} & \multicolumn{2}{|c|}{8086} & \multicolumn{2}{|c|}{4515} & \multicolumn{2}{|r|}{3471} \\
\hline & $\%$ & $\begin{array}{l}\text { Median } \\
\text { (IQR) }\end{array}$ & $\%$ & $\begin{array}{l}\text { Median } \\
\text { (IQR) }\end{array}$ & $\%$ & $\begin{array}{l}\text { Median } \\
\text { (IQR) }\end{array}$ & $\%$ & $\begin{array}{l}\text { Median } \\
\text { (IQR) }\end{array}$ & $\%$ & $\begin{array}{l}\text { Median } \\
\text { (IQR) }\end{array}$ & $\%$ & $\begin{array}{l}\text { Median } \\
\text { (IQR) }\end{array}$ \\
\hline \multicolumn{13}{|c|}{ Randomisation group } \\
\hline Placebo & $28.9 \%$ & & $24.9 \%$ & & $25.0 \%$ & & $25.0 \%$ & & $24.8 \%$ & & $25.8 \%$ & \\
\hline AT & $23.5 \%$ & & $25.2 \%$ & & $24.7 \%$ & & $25.2 \%$ & & $25.2 \%$ & & $25.0 \%$ & \\
\hline$B C$ & $21.4 \%$ & & $25.2 \%$ & & $25.6 \%$ & & $24.1 \%$ & & $25.3 \%$ & & $25.3 \%$ & \\
\hline ATBC & $26.1 \%$ & & $24.6 \%$ & & $24.6 \%$ & & $25.8 \%$ & & $24.7 \%$ & & $23.9 \%$ & \\
\hline Age, years & & $\begin{array}{c}57 \\
(53-61)\end{array}$ & & $\begin{array}{c}57 \\
(54-61)\end{array}$ & & $\begin{array}{c}57 \\
(53-62)\end{array}$ & & $\begin{array}{c}57 \\
(53-61)\end{array}$ & & $\begin{array}{c}56 \\
(52-60)\end{array}$ & & $\begin{array}{c}55 \\
(52-59)\end{array}$ \\
\hline $\mathrm{BMI}, \mathrm{kg} \mathrm{m}^{-2}$ & & $\begin{array}{c}25.5 \\
(23.0-28.2)\end{array}$ & & $\begin{array}{c}26.1 \\
(23.7-28.6)\end{array}$ & & $\begin{array}{c}25.9 \\
(23.7-28.5)\end{array}$ & & $\begin{array}{c}25.9 \\
(23.8-28.4)\end{array}$ & & $\begin{array}{c}26.0 \\
(23.7-28.6)\end{array}$ & & $\begin{array}{c}26.1 \\
(23.8-28.5)\end{array}$ \\
\hline $\begin{array}{l}\text { Greater than } \\
\text { elementary school }\end{array}$ & $24.7 \%$ & & $27.8 \%$ & & $24.7 \%$ & & $20.0 \%$ & & $18.6 \%$ & & $17.2 \%$ & \\
\hline Currently married & $73.3 \%$ & & $74.7 \%$ & & 79.7\% & & $83.5 \%$ & & $83.9 \%$ & & $82.6 \%$ & \\
\hline $\begin{array}{l}\text { Age when starting } \\
\text { to smoke, years }\end{array}$ & & $\begin{array}{c}19 \\
(17-20)\end{array}$ & & $\begin{array}{c}19 \\
(17-21)\end{array}$ & & $\begin{array}{c}19 \\
(17-21)\end{array}$ & & $\begin{array}{c}19 \\
(17-21)\end{array}$ & & $\begin{array}{c}19 \\
(17-20)\end{array}$ & & $\begin{array}{c}18 \\
(16-20)\end{array}$ \\
\hline Years of smoking & & $\begin{array}{c}37 \\
(31-42)\end{array}$ & & $\begin{array}{c}37 \\
(30-42)\end{array}$ & & $\begin{array}{c}37 \\
(31-42)\end{array}$ & & $\begin{array}{c}36 \\
(31-42)\end{array}$ & & $\begin{array}{c}36 \\
(31-41)\end{array}$ & & $\begin{array}{c}36 \\
(32-41)\end{array}$ \\
\hline $\begin{array}{l}\text { Total no. of } \\
\text { cigarettes per day }\end{array}$ & & $\begin{array}{c}20 \\
(15-25)\end{array}$ & & $\begin{array}{c}20 \\
(12-25)\end{array}$ & & $\begin{array}{c}20 \\
(15-25)\end{array}$ & & $\begin{array}{c}20 \\
(15-25)\end{array}$ & & $\begin{array}{c}20 \\
(15-25)\end{array}$ & & $\begin{array}{c}20 \\
(20-30)\end{array}$ \\
\hline Alcohol $\left(\right.$ g day $\left.^{-1}\right)$ & & $\begin{array}{c}15.92 \\
(4.10-32.39)\end{array}$ & & $\begin{array}{c}18.82 \\
(6.50-36.95)\end{array}$ & & $\begin{array}{c}12.99 \\
(3.85-27.86)\end{array}$ & & $\begin{array}{c}10.09 \\
(2.19-23.83)\end{array}$ & & $\begin{array}{c}8.77 \\
(1.83-22.86)\end{array}$ & & $\begin{array}{c}7.22 \\
(1.11-19.41)\end{array}$ \\
\hline Non-tea drinkers & $38.8 \%$ & & $39.6 \%$ & & $57.1 \%$ & & $68.4 \%$ & & $74.5 \%$ & & $81.6 \%$ & \\
\hline $\begin{array}{l}\text { Serum cholesterol, } \\
\mathrm{mmoll}^{-1}\end{array}$ & & $\begin{array}{c}5.94 \\
(5.21-6.67)\end{array}$ & & $\begin{array}{c}6.06 \\
(5.39-6.82)\end{array}$ & & $\begin{array}{c}6.15 \\
(5.41-6.91)\end{array}$ & & $\begin{array}{c}6.20 \\
(5.48-6.97)\end{array}$ & & $\begin{array}{c}6.22 \\
(5.51-7.04)\end{array}$ & & $\begin{array}{c}6.20 \\
(5.47-7.02)\end{array}$ \\
\hline $\begin{array}{l}\text { History of diabetes } \\
\text { mellitus, } n, \%\end{array}$ & $5.0 \%$ & & $5.0 \%$ & & $4.2 \%$ & & $3.7 \%$ & & $4.3 \%$ & & $4.3 \%$ & \\
\hline $\begin{array}{l}\text { Hepatitis B surface } \\
\text { antigen positive } e^{\text {a }}\end{array}$ & $0 \%$ & & $0 \%$ & & $1.8 \%$ & & $0.5 \%$ & & $0.8 \%$ & & $0 \%$ & \\
\hline $\begin{array}{l}\text { Hepatitis B core } \\
\text { antigen positive }^{a}\end{array}$ & $0 \%$ & & $10.1 \%$ & & $7.3 \%$ & & $5.5 \%$ & & $7.0 \%$ & & $5.7 \%$ & \\
\hline Hepatitis C positive ${ }^{a}$ & $0 \%$ & & $1.0 \%$ & & $0.9 \%$ & & $0 \%$ & & $0 \%$ & & $0 \%$ & \\
\hline
\end{tabular}

liver cancer: RR per cup per day $=0.81,95 \%$ CI: $0.72-0.92$; chronic liver disease mortality: $\mathrm{RR}=0.57,95 \% \mathrm{CI}$ : $0.50-0.66$ ) and 5 years of follow-up (incident liver cancer: $\mathrm{RR}=0.81,95 \% \mathrm{CI}$ : $0.71-0.92$; chronic liver disease mortality: $\mathrm{RR}=0.56,95 \% \mathrm{CI}: 0.48-0.65)$ and in cases occurring during the first 10 years (incident liver cancer: $\mathrm{RR}=0.81,95 \% \mathrm{CI}: 0.66-0.98$; chronic liver disease mortality: $\mathrm{RR}=0.53$, 95\% CI: $0.44-0.64$ ) or last 10 years (incident liver cancer: $\mathrm{RR}=0.83,95 \% \mathrm{CI}$ : 0.71-0.96; chronic liver disease mortality: $\mathrm{RR}=0.57,95 \% \mathrm{CI}$ : $0.48-0.69)$ of follow-up.

We evaluated whether associations of coffee intake with incident liver cancer and chronic liver disease mortality varied by a number of risk factors including age, BMI, years of smoking, number of cigarettes smoked per day, alcohol intake and serum cholesterol. For incident liver cancer, we observed modest differences between some subgroups. For example, associations for coffee drinking appeared to be somewhat weaker among those who were younger
$(<57$ years; RR per cup per day $=0.94,95 \%$ CI: $0.80-1.10)$, had a lower BMI $\left(<26 \mathrm{~kg} \mathrm{~m}^{-2}\right.$; RR per cup per day $=0.93,95 \%$ CI: 0.76-1.12) and smoked for a shorter number of years (36 years; RR per cup per day $=0.93,95 \%$ CI: $0.77-1.13)$ than those who were older $(\mathrm{RR}=0.73$, 95\% CI: 0.61-0.86), had a higher BMI $(\mathrm{RR}=0.77,95 \% \mathrm{CI}: 0.67-0.90)$ and smoked for a longer period of time $(R R=0.76,955 \mathrm{CI}: 0.66-0.89)$. However, these potential differences were not statistically significant (all $P$-for-interaction $>0.07$ ) and thus likely due to chance. For chronic liver disease mortality, we observed little difference across each stratifying variable, and again we observed no statistical evidence for an interaction (all $P$-for-interaction $>0.09$ ) (Supplementary Tables 2 and 3 ).

We also examined whether associations varied by coffee preparation methods. Boiling (about 21\%) and filtering (about $71 \%$ ) were the two most common methods of coffee preparation 
Table 2. Association of coffee consumption with incident liver cancer and mortality from chronic liver disease, ATBC Study (Presented as RRs and $95 \% \mathrm{Cls})$

Incident liver cancer

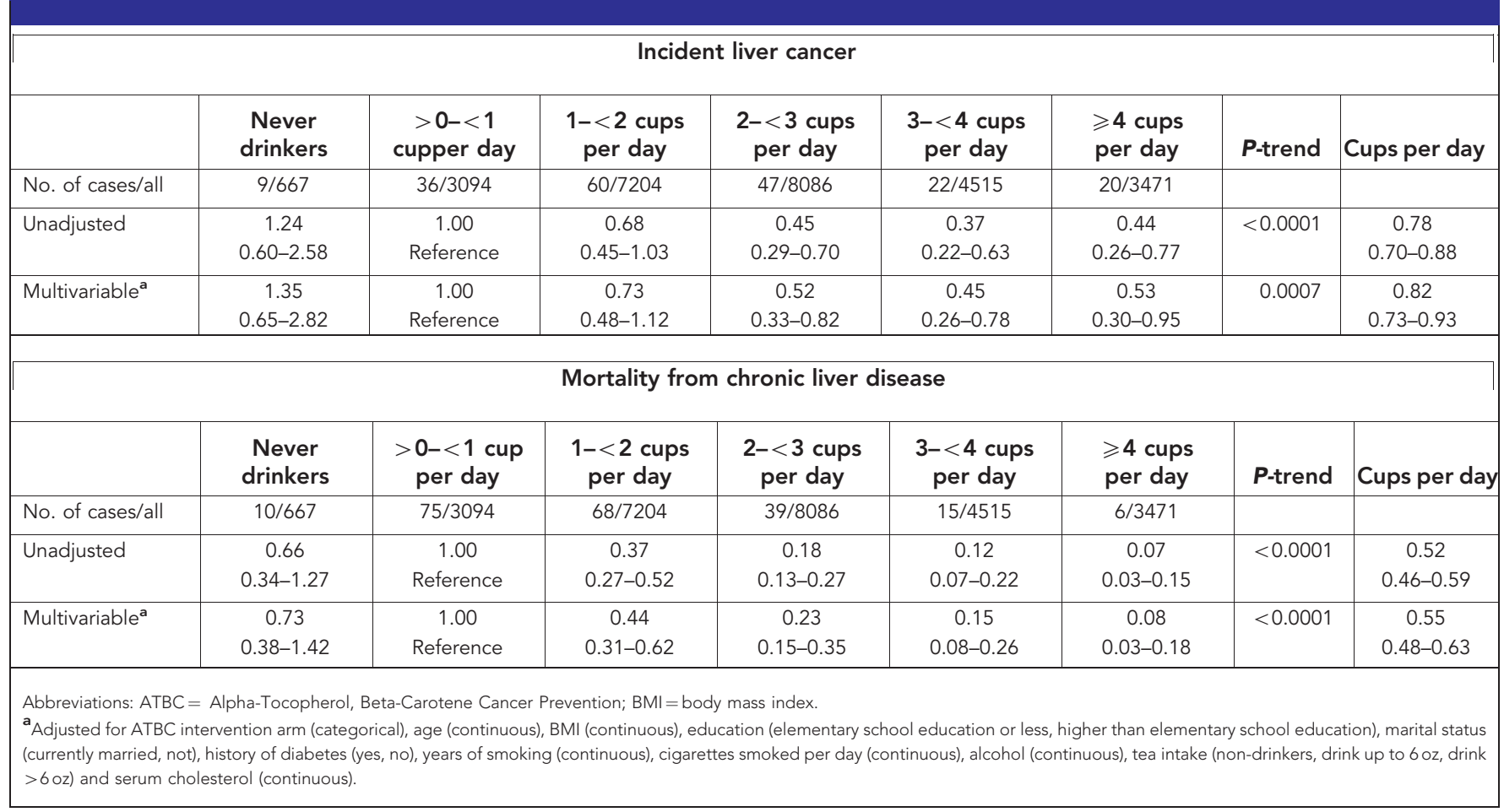

among the 20737 men with information on coffee preparation. These 20737 men were similar to the overall analytic sample of 27037 men in terms of baseline characteristics including age, BMI, education, smoking, alcohol intake and history of diabetes. This yielded 130 men who were diagnosed with incident liver cancer and 109 men who died from chronic liver disease who had reported drinking boiled or filtered coffee. The results for consumption of boiled and filtered coffee were similar in this subcohort: for liver cancer, total consumption (cups per day) $\mathrm{RR}=0.83 \quad(95 \% \quad \mathrm{CI}: \quad 0.72-0.95)$, boiled coffee $\mathrm{RR}=0.85$ (95\% CI: $0.65-1.11$ ), filtered coffee $\mathrm{RR}=0.82$ (95\% CI: 0.69-0.98); for chronic liver disease mortality, total consumption (cups per day) $\mathrm{RR}=0.55 \quad(95 \% \quad \mathrm{CI}: 0.47-0.65)$, boiled coffee $\mathrm{RR}=0.62$ (95\% CI: $0.43-0.88$ ), filtered coffee $R R=0.50$ (95\% CI: $0.40-0.63$; Table 3).

\section{DISCUSSION}

In this prospective cohort of Finnish male smokers with low prevalence of $\mathrm{HBV}$ and $\mathrm{HCV}$, we found those who consumed more coffee had a lower risk of incident liver cancer and mortality from chronic liver disease. Relative to coffee drinkers who drank $<1$ cup per day, men who drank $>2$ cups per day had a nearly $50 \%$ reduction in risk for liver cancer, whereas for mortality from chronic liver disease, the reduction was over $90 \%$ for men who drank $>4$ cups per day. These notable inverse associations were stable during the follow-up period, and observed even among those without any history of diabetes and within different strata such as age, BMI and serum cholesterol levels. Although both alcohol and smoking are risk factors for chronic liver disease and liver cancer (Fan and Farrell, 2009; Altamirano and Bataller, 2010), adjustment for alcohol and smoking had little effect on our risk estimates. Furthermore, neither smoking duration nor intensity modified the association of coffee with liver cancer or chronic liver disease and results were similar in men who drank low and high amounts of alcohol.

The very strong nature of the observed inverse associations of coffee with incident liver cancer and chronic liver disease mortality may raise questions about the plausibility of these observations. However, findings of an inverse association of coffee intake with both liver cancer and chronic liver disease have been reported in previous studies and are consistent with the literature. Coffee intake has been reported by several cross-sectional studies to be inversely associated with serum liver enzymes gammaglutamyltransferase (Arnesen et al, 1986; Kono et al, 1994; Poikolainen and Vartiainen, 1997; Tanaka et al, 1998; Nakanishi et al, 2000), alanine aminotransferase and aspartate aminotransferase (Ruhl and Everhart, 2005), which are markers of liver injury. Coffee intake was also associated inversely with liver cirrhosis in two large US prospective cohort studies (Tverdal and Skurtveit, 2003; Klatsky et al, 2006). For liver cancer, inverse associations with coffee intake have been observed in case-control studies based in Italy, Greece and Japan (Bravi et al, 2007, 2009; Larsson and Wolk, 2007) as well as prospective cohort studies in Asia (Bravi et al, 2007, 2009; Larsson and Wolk, 2007; Johnson et al, 2011; Yu et al, 2011) and one in Finland (Hu et al, 2008).

Coffee contains a large number of compounds, many of which are biologically active. The mechanisms by which coffee may possibly influence the development and progression of liver cancer and chronic liver disease could be related to the antioxidant properties of several compounds. A number of in vitro and in vivo study studies have demonstrated that chlorogenic acid, a component of green coffee beans, exhibits antioxidant, anti-inflammatory and antiproliferative properties (Saad et al, 1998; Iwai et al, 2004; Sato et al, 2011; Yun et al, 2012; Shi et al, 2013). Diterpenes such as cafestol and kahweol induce phase II enzyme activity and decrease chemically induced liver DNA adducts (Cavin et al, 1998, 2002; Huber et al, 2002a,b). 
Table 3. Association of coffee by preparation type with incident liver cancer and mortality from chronic liver disease, ATBC Study (Presented as RRs and $95 \% \mathrm{Cls})$

\section{Incident liver cancer}

\begin{tabular}{|c|c|c|c|c|c|c|c|}
\hline $\begin{array}{l}\text { Filtered method of preparing } \\
\text { coffee }^{a}\end{array}$ & $\begin{array}{l}>0-<1 \text { cup } \\
\text { per day }\end{array}$ & $\begin{array}{c}1-<2 \text { cups } \\
\text { per day }\end{array}$ & $\begin{array}{c}2-<3 \text { cups } \\
\text { per day }\end{array}$ & $\begin{array}{l}3-<4 \text { cups } \\
\text { per day }\end{array}$ & $\begin{array}{l}\geqslant 4 \text { cups } \\
\text { per day }\end{array}$ & $\boldsymbol{P}$-trend & Cups per day \\
\hline No. of cases/all & $\begin{array}{c}16 / 1467 \\
1.00 \\
\text { Reference }\end{array}$ & $\begin{array}{c}34 / 4081 \\
0.80 \\
0.44-1.47\end{array}$ & $\begin{array}{c}26 / 4575 \\
0.54 \\
0.29-1.03\end{array}$ & $\begin{array}{c}9 / 2595 \\
0.34 \\
0.15-0.78\end{array}$ & $\begin{array}{c}12 / 1931 \\
0.61 \\
0.28-1.34\end{array}$ & 0.03 & $\begin{array}{c}0.82 \\
0.69-0.98\end{array}$ \\
\hline Boiled method of preparing coffee ${ }^{a}$ & $\begin{array}{l}>0 \text { to }<1 \text { cup } \\
\text { per day }\end{array}$ & $\begin{array}{c}1 \text { to }<2 \text { cups } \\
\text { per day }\end{array}$ & $\begin{array}{l}2 \text { to }<3 \text { cups } \\
\text { per day }\end{array}$ & $\begin{array}{c}3 \text { to }<4 \text { cups } \\
\text { per day }\end{array}$ & $\begin{array}{l}\geq 4 \text { cups } \\
\text { per day }\end{array}$ & $\boldsymbol{P}$-trend & Cups per day \\
\hline No. of cases/all & $\begin{array}{c}7 / 427 \\
1.00 \\
\text { Reference }\end{array}$ & $\begin{array}{c}10 / 1016 \\
0.60 \\
0.23-1.57\end{array}$ & $\begin{array}{c}5 / 1358 \\
0.25 \\
0.08-0.80\end{array}$ & $\begin{array}{c}7 / 781 \\
0.60 \\
0.21-1.75\end{array}$ & $\begin{array}{c}4 / 667 \\
0.40 \\
0.12-1.40\end{array}$ & 0.19 & $\begin{array}{c}0.85 \\
0.65-1.11\end{array}$ \\
\hline \multicolumn{8}{|c|}{ Mortality from chronic liver disease } \\
\hline $\begin{array}{l}\text { Filtered method of preparing } \\
\text { coffee }^{b}\end{array}$ & $\begin{array}{l}>0-<1 \text { cup } \\
\text { per day }\end{array}$ & $\begin{array}{c}1-<2 \text { cups } \\
\text { per day }\end{array}$ & $\begin{array}{c}2-<3 \text { cups } \\
\text { per day }\end{array}$ & $\begin{array}{l}3-<4 \text { cups } \\
\text { per day }\end{array}$ & $\begin{array}{l}\geqslant 4 \text { cups } \\
\text { per day }\end{array}$ & $P$-trend & Cups per day \\
\hline No. of cases/all & $\begin{array}{c}28 / 1467 \\
1.00 \\
\text { Reference }\end{array}$ & $\begin{array}{c}30 / 4081 \\
0.43 \\
0.25-0.73\end{array}$ & $\begin{array}{c}17 / 4575 \\
0.22 \\
0.12-0.40\end{array}$ & $\begin{array}{c}7 / 2595 \\
0.14 \\
0.06-0.33\end{array}$ & $\begin{array}{c}2 / 1931 \\
0.05 \\
0.01-0.22\end{array}$ & $<0.0001$ & $\begin{array}{c}0.50 \\
0.40-0.63\end{array}$ \\
\hline Boiled method of preparing coffee ${ }^{b}$ & $\begin{array}{l}>0-<1 \text { cup } \\
\text { per day }\end{array}$ & $\begin{array}{l}1-<2 \text { cups } \\
\text { per day }\end{array}$ & $\begin{array}{l}2-<3 \text { cups } \\
\text { per day }\end{array}$ & $\begin{array}{l}3-<4 \text { cups } \\
\text { per day }\end{array}$ & $\begin{array}{l}\geqslant 4 \text { cups } \\
\text { per day }\end{array}$ & $P$-trend & Cups per day \\
\hline No. of cases/all & $\begin{array}{c}7 / 427 \\
1.00 \\
\text { Reference }\end{array}$ & $\begin{array}{c}8 / 1016 \\
0.52 \\
0.19-1.45\end{array}$ & $\begin{array}{c}5 / 1358 \\
0.26 \\
0.08-0.82\end{array}$ & $\begin{array}{c}2 / 781 \\
0.16 \\
0.03-0.79\end{array}$ & $\begin{array}{c}2 / 667 \\
0.19 \\
0.04-0.94\end{array}$ & 0.005 & $\begin{array}{c}0.62 \\
0.43-0.88\end{array}$ \\
\hline \multicolumn{8}{|c|}{$\begin{array}{l}\text { Abbreviations: ATBC = Alpha-Tocopherol, Beta-Carotene Cancer Prevention; BMI=body mass index. } \\
\text { aAdjusted for intake of coffee prepared by boiling (categorical), never drinker (yes, no), other coffee intake (yes, no), ATBC intervention arm (categorical), age (continuous), BMI (continuous), } \\
\text { education (elementary school education or less, higher than elementary school education), marital status (currently married, not), history of diabetes (yes, no), years of smoking (continuous), } \\
\text { cigarettes smoked per day (continuous), alcohol (continuous), tea intake (non-drinkers, drink up to } 6 \text { oz, drink > } 6 \text { oz) and serum cholesterol (continuous). } \\
\text { bAdjusted for intake of coffee prepared by filtering (categorical), never drinker (yes, no), other coffee intake (yes, no), ATBC intervention arm (categorical), age (continuous), BMI (continuous), } \\
\text { education (elementary school education or less, higher than elementary school education), marital status (currently married, not), history of diabetes (yes, no), years of smoking (continuous), } \\
\text { cigarettes smoked per day (continuous), alcohol (continuous), tea intake (non-drinkers, drink up to } 6 \text { oz, drink > } 6 \text { oz) and serum cholesterol (continuous). }\end{array}$} \\
\hline
\end{tabular}

It has been noted that the levels of cafestol and kahweol are higher in Scandinavian-styled boiled and Turkish coffee compared with drip filtered or instant coffee (Urgert et al, 1995; Gross et al, 1997). In this study, we observed that both boiled and filtered coffee were inversely associated with chronic liver disease mortality and liver cancer, suggesting that the effects of coffee on liver cancer and chronic liver disease are likely due to components that are present in coffee prepared both ways. To our knowledge, this is the first time where the association of coffee with liver cancer and chronic liver disease was evaluated by coffee preparation method.

Alternatively, coffee may affect insulin and glucose signalling. Coffee has consistently been inversely associated with type 2 diabetes in prospective cohort studies (Agardh et al, 2004; SalazarMartinez et al, 2004; van Dam et al, 2004; Yamaji et al, 2004; Huxley et al, 2009). As diabetes has consistently been associated with higher risk of liver cancer (El-Serag et al, 2006) and liver disease (Picardi et al, 2006), coffee could possibly benefit the liver through regulation of insulin secretion, improvement of glucose tolerance and other related metabolic pathways (Tunnicliffe and Shearer, 2008). However, additional adjustment for diabetes had little effect on our observed associations. Adjustment for insulin resistance in a previously published study of coffee and liver disease progression was also reported to have no effect on the association (Freedman et al, 2009).

Associations of coffee with incident liver cancer and mortality from chronic liver disease could also reflect underlying liver disease, as coffee intake has been associated with fibrosis and cirrhosis in previous studies and as caffeine is metabolised in the liver, those with underlying liver disease may drink less coffee. We attempted to minimise this possibility by excluding individuals with self-reported cirrhosis at baseline. In addition, the observed associations remained after lag analyses, further indicating that reverse causality was an unlikely explanation for our findings. Associations were also similar in those with both higher and lower serum cholesterol levels at baseline, which has been previously associated with liver disease and subsequent liver cancer in this and other cohorts (Cicognani et al, 1997; Ahn et al, 2009; Kitahara et al, 2011). Previous studies have also found inverse associations between coffee and liver disease progression among those with fibrosis at study baseline (Freedman et al, 2009), further suggesting that our results do not simply reflect pre-existing liver disease.

Our study has several strengths and limitations. The prospective design limits the possibility of recall bias affecting our results as participants reported their coffee intake without knowledge of their future disease occurrence. We also had a long follow-up time of 24 years permitting assessment of reverse causality through lag analyses. The extensive baseline questionnaire allowed us to adjust for a number of potential confounders such as BMI, history of diabetes, alcohol intake, and HBV and HCV status. In particular, information on coffee preparation methods allowed us to explore whether the associations between coffee intake and disease risk differed by brewing method. However, as the primary purpose of 
the study was to evaluate the use of vitamin supplements on lung cancer, associations of coffee with liver cancer or chronic liver disease mortality are secondary outcomes. Yet, similarity to previous studies in Western and Asian populations lends support to our findings. Also, we did not have any information on whether intake of coffee was caffeinated or not and coffee intake was assessed at only a single time. We possessed information on HBV and HCV for only a subset of our cohort; however, the very low prevalence of these infections in this subset $(99.2 \%$ and $98.5 \%$ were negative for $\mathrm{HBsAg}$ and $\mathrm{HCV}$, respectively) suggests nearly all cases occurred in the absence of $\mathrm{HBV}$ and $\mathrm{HCV}$ infection, and as such, HBV and HCV had little effect on our risk estimates. In addition, we lacked assessment of underlying liver disease, although men with cirrhosis were excluded from the cohort at baseline and associations did not vary over 24 years of follow-up. Furthermore, the evaluation of these associations among male smokers limits our ability to generalise to other populations. Finally, it is possible that our observations, despite our consideration of a number of known and potential confounders, may be due to uncontrolled confounding or bias as is always true of observational studies.

In summary, we observed that high coffee intake was associated with a statistically significant, reduced risk of incident liver cancer and mortality from chronic liver disease in a Finnish prospective cohort study. Although different preparation methods for coffee can influence the types of compounds found in coffee, we observed that both filtered and boiled coffee were inversely associated with liver cancer and mortality from chronic liver disease. A growing body of literature supports a beneficial role for coffee in liver cancer and liver disease. Future studies will be needed to elucidate what components of coffee may contribute to these associations.

\section{ACKNOWLEDGEMENTS}

This research was supported by the Intramural Research Program, Division of Cancer Epidemiology and Genetics, National Cancer Institute, National Institutes of Health, Department of Health and Human Services and US Public Health Service contracts (N01CN-45165, N01-RC-45035 and N01-RC-37004). The sponsor reviewed and approved final submission but had no role in the design and conduct of the study; collection, management, analysis and interpretation of the data; and preparation of the manuscript.

\section{CONFLICT OF INTEREST}

The authors declare no conflict of interest.

\section{REFERENCES}

Agardh EE, Carlsson S, Ahlbom A, Efendic S, Grill V, Hammar N, Hilding A, Ostenson CG (2004) Coffee consumption, type 2 diabetes and impaired glucose tolerance in Swedish men and women. J Intern Med 255(6): 645-652.

Ahn J, Lim U, Weinstein SJ, Schatzkin A, Hayes RB, Virtamo J, Albanes D (2009) Prediagnostic total and high-density lipoprotein cholesterol and risk of cancer. Cancer Epidemiol Biomarkers Prev 18(11): 2814-2821.

Altamirano J, Bataller R (2010) Cigarette smoking and chronic liver diseases. Gut 59(9): 1159-1162.

Arnesen E, Huseby NE, Brenn T, Try K (1986) The Tromso Heart Study: distribution of, and determinants for, gamma-glutamyltransferase in a free-living population. Scand J Clin Lab Invest 46(1): 63-70.

Bravi F, Bosetti C, Tavani A, Bagnardi V, Gallus S, Negri E, Franceschi S, La Vecchia C (2007) Coffee drinking and hepatocellular carcinoma risk: a meta-analysis. Hepatology 46(2): 430-435.
Bravi F, Bosetti C, Tavani A, La Vecchia C (2009) Coffee drinking and hepatocellular carcinoma: an update. Hepatology 50(4): 1317-1318.

Cavin C, Holzhaeuser D, Scharf G, Constable A, Huber WW, Schilter B (2002) Cafestol and kahweol, two coffee specific diterpenes with anticarcinogenic activity. Food Chem Toxicol 40(8): 1155-1163.

Cavin C, Holzhauser D, Constable A, Huggett AC, Schilter B (1998) The coffee-specific diterpenes cafestol and kahweol protect against aflatoxin B1-induced genotoxicity through a dual mechanism. Carcinogenesis 19(8): 1369-1375.

Chuang SC, La Vecchia C, Boffetta P (2009) Liver cancer: descriptive epidemiology and risk factors other than HBV and HCV infection. Cancer letters 286(1): 9-14.

Cicognani C, Malavolti M, Morselli-Labate AM, Zamboni L, Sama C, Barbara L (1997) Serum lipid and lipoprotein patterns in patients with liver cirrhosis and chronic active hepatitis. Arch Intern Med 157(7): 792-796.

El-Serag HB, Hampel H, Javadi F (2006) The association between diabetes and hepatocellular carcinoma: a systematic review of epidemiologic evidence. Clin Gastroenterol Hepatol 4(3): 369-380.

El-Serag HB, Rudolph KL (2007) Hepatocellular carcinoma: epidemiology and molecular carcinogenesis. Gastroenterology 132(7): 2557-2576.

Fan JG, Farrell GC (2009) Prevention of hepatocellular carcinoma in nonviralrelated liver diseases. J Gastroenterol Hepatol 24(5): 712-719.

Ferlay J, Shin HR, Bray F, Forman D, Mathers C, Parkin DM (2010) Estimates of worldwide burden of cancer in 2008: GLOBOCAN 2008. Int J Cancer 127(12): 2893-2917.

Freedman ND, Everhart JE, Lindsay KL, Ghany MG, Curto TM, Shiffman ML, Lee WM, Lok AS, Di Bisceglie AM, Bonkovsky HL, Hoefs JC, Dienstag JL, Morishima C, Abnet CC, Sinha R (2009) Coffee intake is associated with lower rates of liver disease progression in chronic hepatitis C. Hepatology 50(5): 1360-1369.

Gross G, Jaccaud E, Huggett AC (1997) Analysis of the content of the diterpenes cafestol and kahweol in coffee brews. Food Chem Toxicol 35(6): 547-554.

Hu G, Tuomilehto J, Pukkala E, Hakulinen T, Antikainen R, Vartiainen E, Jousilahti P (2008) Joint effects of coffee consumption and serum gammaglutamyltransferase on the risk of liver cancer. Hepatology 48(1): 129-136.

Huber WW, Prustomersky S, Delbanco E, Uhl M, Scharf G, Turesky RJ, Thier R, Schulte-Hermann R (2002a) Enhancement of the chemoprotective enzymes glucuronosyl transferase and glutathione transferase in specific organs of the rat by the coffee components kahweol and cafestol. Arch Toxicol 76(4): 209-217.

Huber WW, Scharf G, Rossmanith W, Prustomersky S, Grasl-Kraupp B, Peter B, Turesky RJ, Schulte-Hermann R (2002b) The coffee components kahweol and cafestol induce gamma-glutamylcysteine synthetase, the rate limiting enzyme of chemoprotective glutathione synthesis, in several organs of the rat. Arch Toxicol 75(11-12): 685-694.

Huxley R, Lee CM, Barzi F, Timmermeister L, Czernichow S, Perkovic V, Grobbee DE, Batty D, Woodward M (2009) Coffee, decaffeinated coffee, and tea consumption in relation to incident type 2 diabetes mellitus: a systematic review with meta-analysis. Arch Intern Med 169(22): 2053-2063.

Iwai K, Kishimoto N, Kakino Y, Mochida K, Fujita T (2004) In vitro antioxidative effects and tyrosinase inhibitory activities of seven hydroxycinnamoyl derivatives in green coffee beans. J Agric Food Chem 52(15): 4893-4898.

Jee SH, He J, Appel LJ, Whelton PK, Suh I, Klag MJ (2001) Coffee consumption and serum lipids: a meta-analysis of randomized controlled clinical trials. Am J Eepidemiol 153(4): 353-362.

Johnson S, Koh WP, Wang R, Govindarajan S, Yu MC, Yuan JM (2011) Coffee consumption and reduced risk of hepatocellular carcinoma: findings from the Singapore Chinese Health Study. Cancer Causes Control 22(3): 503-510.

Kitahara CM, Berrington de Gonzalez A, Freedman ND, Huxley R, Mok Y, Jee SH, Samet JM (2011) Total cholesterol and cancer risk in a large prospective study in Korea. J Clin Oncol 29(12): 1592-1598.

Klatsky AL, Morton C, Udaltsova N, Friedman GD (2006) Coffee, cirrhosis, and transaminase enzymes. Arch Intern Med 166(11): 1190-1195.

Kono S, Shinchi K, Imanishi K, Todoroki I, Hatsuse K (1994) Coffee and serum gamma-glutamyltransferase: a study of self-defense officials in Japan. Am J Epidemiol 139(7): 723-727.

Korhonen P, Malila N, Pukkala E, Teppo L, Albanes D, Virtamo J (2002) The Finnish Cancer Registry as follow-up source of a large trial cohortaccuracy and delay. Acta Oncologica (Stockholm, Sweden) 41(4): 381-388. 
Larsson SC, Wolk A (2007) Coffee consumption and risk of liver cancer: a meta-analysis. Gastroenterology 132(5): 1740-1745.

Majer BJ, Hofer E, Cavin C, Lhoste E, Uhl M, Glatt HR, Meinl W, Knasmuller S (2005) Coffee diterpenes prevent the genotoxic effects of 2-amino-1-methyl-6-phenylimidazo[4,5-b]pyridine (PhIP) and $\mathrm{N}$-nitrosodimethylamine in a human derived liver cell line (HepG2). Food Chem Toxicol 43(3): 433-441.

McGlynn KA, Tsao L, Hsing AW, Devesa SS, Fraumeni Jr JF (2001) International trends and patterns of primary liver cancer. Int $J$ Cancer 94(2): 290-296.

Modi AA, Feld JJ, Park Y, Kleiner DE, Everhart JE, Liang TJ, Hoofnagle JH (2010) Increased caffeine consumption is associated with reduced hepatic fibrosis. Hepatology 51(1): 201-209.

Muriel P, Arauz J (2010) Coffee and liver diseases. Fitoterapia 81(5): 297-305.

Nakanishi N, Nakamura K, Suzuki K, Tatara K (2000) Effects of coffee consumption against the development of liver dysfunction: a 4-year follow-up study of middle-aged Japanese male office workers. Ind Health 38(1): 99-102.

Noordzij M, Uiterwaal CS, Arends LR, Kok FJ, Grobbee DE, Geleijnse JM (2005) Blood pressure response to chronic intake of coffee and caffeine: a meta-analysis of randomized controlled trials. J Hypertension 23(5): 921-928.

Picardi A, D'Avola D, Gentilucci UV, Galati G, Fiori E, Spataro S, Afeltra A (2006) Diabetes in chronic liver disease: from old concepts to new evidence. Diabetes/Metabolism Res Rev 22(4): 274-283.

Pietinen P, Hartman AM, Haapa E, Rasanen L, Haapakoski J, Palmgren J, Albanes D, Virtamo J, Huttunen JK (1988) Reproducibility and validity of dietary assessment instruments. I. A self-administered food use questionnaire with a portion size picture booklet. Am J Epidemiol 128(3): 655-666.

Poikolainen K, Vartiainen E (1997) Determinants of gammaglutamyltransferase: positive interaction with alcohol and body mass index, negative association with coffee. Am J Epidemiol 146(12): 1019-1024.

Ratnayake WM, Hollywood R, O’Grady E, Stavric B (1993) Lipid content and composition of coffee brews prepared by different methods. Food Chem Toxicol 31(4): 263-269.

Ruhl CE, Everhart JE (2005) Coffee and caffeine consumption reduce the risk of elevated serum alanine aminotransferase activity in the United States. Gastroenterology 128(1): 24-32.

Saad MF, Khan A, Sharma A, Michael R, Riad-Gabriel MG, Boyadjian R, Jinagouda SD, Steil GM, Kamdar V (1998) Physiological insulinemia acutely modulates plasma leptin. Diabetes 47(4): 544-549.

Salazar-Martinez E, Willett WC, Ascherio A, Manson JE, Leitzmann MF, Stampfer MJ, Hu FB (2004) Coffee consumption and risk for type 2 diabetes mellitus. Ann Intern Med 140(1): 1-8.
Sato Y, Itagaki S, Kurokawa T, Ogura J, Kobayashi M, Hirano T, Sugawara M, Iseki K (2011) In vitro and in vivo antioxidant properties of chlorogenic acid and caffeic acid. Int J Pharmaceutics 403(1-2): 136-138.

Shi H, Dong L, Jiang J, Zhao J, Zhao G, Dang X, Lu X, Jia M (2013) Chlorogenic acid reduces liver inflammation and fibrosis through inhibition of toll-like receptor 4 signaling pathway. Toxicology 303: 107-114.

Siegel AB, Zhu AX (2009) Metabolic syndrome and hepatocellular carcinoma: two growing epidemics with a potential link. Cancer 115(24): 5651-5661.

Souza MR, Diniz Mde F, Medeiros-Filho JE, Araujo MS (2012) Metabolic syndrome and risk factors for non-alcoholic fatty liver disease. Arquivos De Gastroenterologia 49(1): 89-96.

Tanaka K, Tokunaga S, Kono S, Tokudome S, Akamatsu T, Moriyama T, Zakouji H (1998) Coffee consumption and decreased serum gamma-glutamyltransferase and aminotransferase activities among male alcohol drinkers. Int J Epidemiol 27(3): 438-443.

The ATBC Cancer Prevention Study Group (1994) The alpha-tocopherol, beta-carotene lung cancer prevention study: design, methods, participant characteristics, and compliance. Ann Epidemiol 4(1): 1-10.

Tunnicliffe JM, Shearer J (2008) Coffee, glucose homeostasis, and insulin resistance: physiological mechanisms and mediators. Appl Physiol Nutr Metab 33(6): 1290-1300.

Tverdal A, Skurtveit S (2003) Coffee intake and mortality from liver cirrhosis. Ann Epidemiol 13(6): 419-423.

Urgert R, Vanderweg G, Kosmeijerschuil TG, Vandebovenkamp P, Hovenier R, Katan MB (1995) Levels of the cholesterol-elevating diterpenes cafestol and kahweol in various coffee brews. J Agr Food Chem 43(8): 2167-2172.

van Dam RM, Dekker JM, Nijpels G, Stehouwer CD, Bouter LM, Heine RJ (2004) Coffee consumption and incidence of impaired fasting glucose, impaired glucose tolerance, and type 2 diabetes: the Hoorn Study. Diabetologia 47(12): 2152-2159.

Yamaji T, Mizoue T, Tabata S, Ogawa S, Yamaguchi K, Shimizu E, Mineshita M, Kono S (2004) Coffee consumption and glucose tolerance status in middle-aged Japanese men. Diabetologia 47(12): 2145-2151.

Yu X, Bao Z, Zou J, Dong J (2011) Coffee consumption and risk of cancers: a meta-analysis of cohort studies. BMC Cancer 11: 96.

Yun N, Kang JW, Lee SM (2012) Protective effects of chlorogenic acid against ischemia/reperfusion injury in rat liver: molecular evidence of its antioxidant and anti-inflammatory properties. J Nutr Biochem 23(10): 1249-1255.

This work is published under the standard license to publish agreement. After 12 months the work will become freely available and the license terms will switch to a Creative Commons AttributionNonCommercial-Share Alike 3.0 Unported License.

Supplementary Information accompanies this paper on British Journal of Cancer website (http://www.nature.com/bjc) 